\title{
Sustainable development impacts of nationally determined contributions: assessing the case of mini-grids in Kenya
}

Dal Maso, Mirko; Olsen, Karen Holm; Dong, Yan; Pedersen, Mathilde Brix; Hauschild, Michael Zwicky

Published in:

Climate Policy

Link to article, DOI:

10.1080/14693062.2019.1644987

Publication date:

2020

Document Version

Peer reviewed version

Link back to DTU Orbit

Citation (APA):

Dal Maso, M., Olsen, K. H., Dong, Y., Pedersen, M. B., \& Hauschild, M. Z. (2020). Sustainable development impacts of nationally determined contributions: assessing the case of mini-grids in Kenya. Climate Policy, 20(7), 815-831. https://doi.org/10.1080/14693062.2019.1644987

\section{General rights}

Copyright and moral rights for the publications made accessible in the public portal are retained by the authors and/or other copyright owners and it is a condition of accessing publications that users recognise and abide by the legal requirements associated with these rights.

- Users may download and print one copy of any publication from the public portal for the purpose of private study or research.

- You may not further distribute the material or use it for any profit-making activity or commercial gain

- You may freely distribute the URL identifying the publication in the public portal 


\title{
Sustainable development impacts of nationally determined contributions: assessing the case of mini-grids in Kenya
}

\author{
Mirko Dal Maso ${ }^{\mathrm{a}}$, Karen Holm Olsen ${ }^{\mathrm{a}}$, Yan Dong ${ }^{\mathrm{b}}$, Mathilde Brix Pedersen ${ }^{\mathrm{a}}$ and Michael Zwicky Hauschild \\ aUNEP DTU Partnership, Department of Technology, Management and Economics, Technical University of Denmark, \\ Copenhagen, Denmark; 'Division for Quantitative Sustainability Assessment, Department of Technology, Management and \\ Economics, Technical University of Denmark, Copenhagen, Denmark
}

\begin{abstract}
As of today, access to electricity is still unavailable to 1.1 billion people in the world, half of which live in Sub-Saharan Africa. Projections suggest that this share will increase, leaving millions of people with limited development prospects. Kenya's nationally determined contribution (NDC) to the 2015 Paris Agreement includes a commitment to expand power supply, and in doing so, provide all its citizens with access to electricity. Access in rural areas, where the majority remains unconnected, is planned to be reached through different technologies. These include mini-grids, which are expected to bring multiple sustainable development benefits. However, comprehensive studies looking at synergies and trade-offs between environmental, social, and economic impacts of mini-grids are scarce. Analyzing the expected contribution of mini-grids to targets such as the NDC and the UN Sustainable Development Goals (SDGs) can provide evidence-based decision-support to policymakers, thus promoting well-designed and sustainable rural electrification policies. By using the Initiative for Climate Action Transparency (ICAT) Sustainable Development Methodology, this paper goes beyond the calculation of greenhouse gas (GHG) impacts resulting from access to modern electricity, analyzing also other environmental and socio-economic implications of 146 solar PV mini grids under construction in Kenya. Using specific targets from the SDG framework, the paper presents a combined qualitative and quantitative analysis of the extent to which mini-grids can contribute to the implementation of Kenya's NDC and to sustainable development priorities.
\end{abstract}

Key policy insights

- The deployment of mini-grids is expected to lower the GHG emissions of the villages currently without access to electricity by $71 \%$.

- This contributes to $0.4 \%$ of the current NDC target for the power sector, in line with the capacity of the systems analyzed.

- This action is expected to also bring about positive impacts on electricity access, indoor air quality, healthcare, education and economic activities, which are found to contribute to 16 SDG targets.

- Apart from the economic investment required, possible negative impacts are associated with the electronic waste generated at the end-of-life of the mini- grids.

- Accounting for sustainable development impacts of policies can increase support among policymakers for climate action, and ultimately raise ambition.

ARTICLE HISTORY

Received 26 December 2018

Accepted 13 July 2019

KEYWORDS

Sustainable development goals (SDGs); nationally determined contribution (NDC); sustainability assessment; solar PV mini- grids; mitigation pathways; transparency 


\section{Introduction}

In line with the 2015 Paris Agreement, almost all countries of the world have committed to nationally determined contributions (NDCs) to limit global temperature rise, adapt to changes already occurring, and regularly increase their efforts over time. Countries have also committed to global Sustainable Development Goals (SDGs) through the 2030 UN Agenda for Sustainable Development. Among the 17 SDGs, SDG 7 calls for ensuring access to affordable, reliable, sustainable and modern energy for all. Achievement of SDG 7 is interlinked with many other goals, particularly ending poverty (SDG 1), creating jobs and economic growth (SDG 8) and combating climate change (SDG 13) (Fuso Nerini et al., 2018; lyer et al., 2018; McCollum et al., 2018). Implementation of the global goals for climate and sustainable development implies synergies and trade-offs at national and global levels specific to the climate policies and actions undertaken (Olsen, Verles, \& Braden, 2018). To maximize the positive impacts, and avoid or minimize the negative ones, assessment of the impacts of climate and development policies and actions is helpful for policy design and steering of implementation towards the desired goals (ICAT, 2018).

In the case of Kenya, the largest economy in East Africa with a population of 48.46 million, of which most (74\%) live in rural areas (World Bank, 2018b), the National Climate Change Action Plan (NCCAP) 2018-2022 calls for climate actions in different sectors to implement Kenya's NDC. Electricity generation, for example, is reported as one of the two sectors with the highest emission reduction potential, mandated to reduce greenhouse gas (GHG) emissions by $9.32 \mathrm{Mt} \mathrm{CO}_{2} \mathrm{eq}$ by 2030 , compared to the business as usual scenario. To achieve this, $2405 \mathrm{MW}$ of new renewable electricity will be deployed, and $300 \mathrm{MW}$ of thermal plants retired, by 2022 (Government of Kenya, 2018).

In remote rural areas, where the cost of grid-extension is prohibitively high, decentralized solar PV solutions have already become the least costly option (Moner-Girona et al., 2018; Szabó, Bódis, Huld, \& Moner-Girona, 2011). Under the NCCAP, solar PV solutions in off-grid areas are projected to comprise $30 \mathrm{MW}$ of the total 2405 $\mathrm{MW}$, and will supply villages which do not yet have electricity access and for which the national grid does not represent a feasible option in the short-term (Government of Kenya, 2018). Access to electricity and the services it provides (lighting, cooling, heating, etc.) creates impacts beyond GHG emission reductions, and it is, in fact, an important enabler for social wellbeing and economic development. However, comprehensive studies of existing climate mitigation options in Kenya looking at synergies and trade-offs between environmental, social and economic impacts are rare. At the same time, while at the global level some initiatives have started to look into broad synergies between NDCs and SDGs (DIE \& SEI, 2019; lyer et al., 2018), and energy and SDGs (Fuso Nerini et al., 2018; Schwerhoff \& Sy, 2017), analysis of the impacts of specific NDC interventions on the SDGs are absent.

In this paper, based on a comprehensive sustainability analysis, we investigate how synergies and trade- offs between NDCs and SDGs can be assessed to enable comparability of the sustainability performance of policies and actions. We do this by applying the existing Sustainable Development Methodology developed by the Initiative for Climate Action Transparency (ICAT) (ICAT, 2018) to the specific case of mini-grids in Kenya, which are part of the NCCAP. The paper thus demonstrates an ex-ante assessment of a specific NDC intervention that goes beyond the calculation of GHG reductions, by capturing broader environmental, social and economic impacts, and represents a contribution to existing literature on links between NDCs and SDGs.

The remainder of the paper is structured as follows. The methods section presents the ICAT Sustainable Development Methodology and describes how the assessed impacts have been linked to the SDG targets. Then, the assessed system is presented, and a description given of the electricity access situation before and after the deployment of the mini-grids. In the results section, the most relevant impact assessment results are reported, from which the impact on the SDGs is derived. In the discussion section, the trade-offs and synergies between the impacts are analyzed, and the usefulness of the assessment for policymakers and for analyses of full NDCs is discussed.

\section{Methods}

\subsection{ICAT sustainable development methodology}

The Initiative for Climate Action Transparency (ICAT) was established in 2016 through a multi-donor Trust Fund managed by the United Nations Office for Project Services (UNOPS). The aim of ICAT is to accelerate climate actions by helping countries and policymakers with tools and support to measure and assess the wider sustainable development impacts of actions for NDC implementation. ICAT offers a series of methodology documents, among which the Sustainable Development Methodology helps users to assess the environmental, social and economic impacts of policies and actions (ICAT, 2018). More information on the ICAT Methodology is provided in the Supplementary Material. 
The current case study analysis follows the methodology provided by ICAT in the Sustainable Development Methodology for ex-ante assessments. An ex-ante assessment predicts what the impact of theconsidered policy scenario will be over a defined time period, in comparison with the baseline scenario, defined as the situation most likely to happen in the absence of the policy scenario. The first step of the ICAT Sustainable Development Methodology consists of identifying the impact categories to be analyzed, which can then be assessed qualitatively and quantitatively. Impact categories are selected according to three criteria: relevance, significance, and comprehensiveness. Relevance is assessed based on the main objectives of the policy (Government of Kenya, 2018), national objectives (Government of Kenya, 2013; Ministry of Devolution and Planning of Kenya, 2017), sustainable development priorities described by the SDGs, and stakeholder views on which types of impacts are most important. To assess how stakeholders view the relevance of impact categories, interviews were conducted with ten national stakeholders involved in the energy sector, including policymakers, NGOs, and private and public actors involved in mini-grids deployment and monitoring, reporting and verification (see Table 1 in Supplementary Material for the list of stakeholders, questions asked and answers received). Significant impact categories were selected based on literature on the links between electricity access and development, making up the sources used to perform the assessment (see Table 10 in Supplementary Material for the list of sources used). Ultimately, only impact categories that were either relevant or significant were chosen, while comprehensiveness was ensured by having, in the final list of categories, both positive and negative impact categories from the three dimensions of sustainability (social, economic, and environmental). The list of selected impact categories and the reasoning behind them can be found in Table 2 in the Supplementary Material. The assessment was performed collectively for the 146 mini-grids.

For the qualitative assessment, specific impacts were identified within each impact category. These comprised positive and negative impacts that could arise from the policy, in comparison to the baseline. Each specific impact was assessed according to its likelihood and magnitude, the extent of which were analyzed based on literature. The magnitude of the change was evaluated on a three-step scale (minor, moderate, major), and was considered relative to the broader local conditions related to the impact category or to the maximum potential impact from policy options considered feasible. The likelihood represents the probability of the impact occurring in the future as a result of the policy or action and was evaluated on a five-step scale (very unlikely: $<10 \%$, unlikely: $>10 \%$ and $<33 \%$, possible: $>33 \%$ and $<66 \%$, likely: $>66 \%$ and $<90 \%$, very likely: $>90 \%$ ). Based on magnitude and likelihood, impacts were divided into significant and non-significant (see Figure 7.2 of ICAT, 2018). Both likelihood and magnitude were based on evidence to the extent possible, such as published studies on similar interventions (i.e. mini-grids/rural electrification in Kenya or similar jurisdictions), and complemented with the authors' expert judgment and inputsfrom the stakeholders' interviews mentioned above.

For the quantitative assessment, the impacts of both scenarios were calculated and the difference between the two, representing the impact of the policy, was found. In this case study, Life Cycle Assessment (LCA) was used to quantify the environmental impacts, using the software SimaPro in concurrence with the Ecoinvent database.

The list of data sources and data used for the qualitative and quantitative assessments can be found in Table 10 in the Supplementary Material.

A summary of the assessment results, including the Life Cycle Inventory and full LCA results, as well as an overview of the qualitative impacts, is presented in the Supplementary Material.

\subsection{SDG impact method}

In addition to what the ICAT Methodology currently provides, this paper links sustainable development impacts to the SDGs. After the assessment of the impacts, impact categories and underlying specific impacts were connected to the 169 SDG targets, based on direct linkages (i.e. a category/specific impact measuring what the target describes). The reasoning behind the linkages identified is explained in detail in Table 12 in the Supplementary Material. When, for one impact category, specific impacts were identified, these were linked with the SDG targets. Otherwise, the linkage to the SDG targets with the impact category was used. Colour coding was used to characterize the impact on the SDG targets. For qualitative impacts, the colour coding in Figure 1 is used.

For quantitative impacts, the relative improvement (\%) for the SDG target was calculated using Equation 1 and expressed using the colour coding in Figure 2. When quantitative impacts were connected to the same SDG target and expressed in the same unit, their scores were aggregated.

$$
\text { Relative improvement (ㅇ) } \frac{\text { Policy scenario impact - Baseline scenarioimpact }}{\text { Baseline scenario impact }}
$$




\begin{tabular}{|c|c|c|c|c|c|c|c|}
\hline \multicolumn{2}{|c|}{} & \multicolumn{3}{|c|}{ Magnitude (Negative) } & \multicolumn{3}{c|}{ Magnitude (Positive) } \\
\cline { 2 - 8 } & Score & Major & Moderate & Minor & Minor & Moderate & Major \\
\hline \multirow{4}{*}{} & Very likely & & & & & & \\
\cline { 2 - 8 } & Likely & & & & & & \\
\cline { 2 - 8 } & Possible & & & & & & \\
\cline { 2 - 8 } & Unlikely & & & & & & \\
\cline { 2 - 8 } & Very unlikely & & & & & & \\
\hline
\end{tabular}

Figure 1. SDGs colour coding for qualitative impacts.

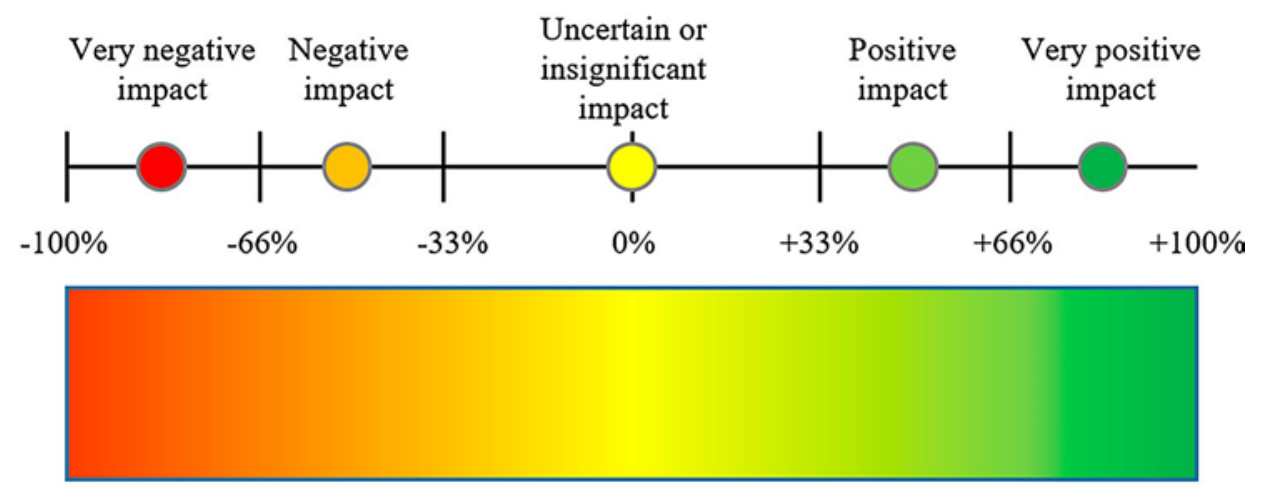

Figure 2. SDGs colour coding for quantitative impacts.

\section{Description of the assessed system}

The study analyses the introduction of a total of 146 solar PV mini-grids. The majority of them belong to the Kenya Off-grid Solar Access Project (K-OSAP) for under-served counties, a project financed by the World Bank and jointly implemented by the Ministry of Energy of Kenya, the Kenya Power and Lighting Company (KPLC) and the Rural Electrification Agency (REA), which consists of 121 solar mini-grids, covering 20,750 households and 6050 businesses. These mini-grids will account for a total capacity of $5 \mathrm{MWp}$ and are planned to be operational by the end of 2023 (World Bank, 2018a). The remaining 25 are public mini-grids under construction by the REA. These solar PV mini-grids are to be completed by 2020 and each of them is expected to supply around 200 customers, resulting in a total solar capacity of $1.5 \mathrm{MWp}$ (Government of Kenya, 2018). After completion, the customers of both mini-grid projects will be subjected to the same tariffs ${ }^{1}$ as users connected to the national grid (Kenya Power \& REA, 2017; Nygaard et al., 2018). The assessment period ranges from the expected year of operation of all mini-grids, 2024, until and including 2030 (7 years), to align with Kenya's NDC, which takes 2030 as a target year.

In the following two sections, the baseline and policy scenario are presented. Since the policy scenario, that is, the implementation of mini-grids, aims to provide access to electricity, which enables lighting and powering electric appliances, the baseline scenario considers the current technologies used to provide access to light and power, in the unconnected villages in Kenya.

\subsection{Baseline scenario}

In the baseline scenario, 31,800 customers not connected to a grid are analyzed. Among these customers, households, businesses, and institutions are represented. The conditions considered are expected to be the same as the present ones and are assumed not to change (i.e. still no electricity access) for the whole time of the assessment. Kerosene lamps were found to be the most common way to overcome the lack of electricity for households in Kenya, with literature reporting the vast majority of the rural population using it as primary source of lighting (Bacon, Bhattacharya, \& Kojima, 2010; Rom, Günther, \& Harri- son, 2017). Based on a survey across under-served counties in Kenya, a monthly kerosene consumption of respectively 4.5 and $4.2 \mathrm{~L}$ is assumed for households and businesses/institutions (Carbon Africa Limited et al., 2015). Especially for villages located in very remote areas, kerosene may be difficult and costly to obtain and therefore the use of battery-powered flashlights is more common (Carbon Africa Limited et al., 2015; Harrison, Scott, \& Hogarth, 2016). An average 
monthly consumption of respectively 4.3 and 6.7 dry cell batteries is assumed for households, and businesses/institutions (Carbon Africa Limited et al., 2015; Van Acker, Szablya, Louie, McLean Sloughter, \& Pirbhai, 2014). Additionally, $5 \%$ of businesses and institutions are assumed to use diesel generators with a daily consumption of 2.78 L/user/day (Carbon Africa Limited et al., 2015; Economic Consulting Associates et al., 2014; Pueyo \& DeMartino, 2018), while $25 \%$ of businesses and $13 \%$ of households have been considered to use Solar Home Systems (SHS) of 20 Wp capacity and a 22 Wh Lithium-ion (Li-ion) battery (Carbon Africa Limited et al., 2015; M-KOPA Solar, 2018).

\subsection{Policy scenario}

The policy scenario analyses the same number of customers for the same period as the baseline, assuming them to be connected to solar PV mini-grids. Based on this assumption, all the technologies outlined in the baseline scenarioare considered to be completely displaced by mini-grids, as reported in the literature (Blodgett, Moder, Kickham, \& Leaf, 2016; Eales, Walley, Buckland, Frame, \& Strachan, 2018; Lenz, Munyehirwe, Peters, \& Sievert, 2017; Pueyo \& DeMartino, 2018). All the 146 mini-grids analyzed are assumed to consist of a $60 \mathrm{kWp}$ silicon crystalline solar panel, a 50 kVA diesel generator as back-up, and a $3200 \mathrm{Ah} 48 \mathrm{~V}$ Li-ion battery, in line with the 25 systems under construction by REA (REA, 2016). The expected lifetime is reported to be 25 years for the panel and 20 years for the battery (REA, 2016). The impacts from the system have been modelled to represent only the period until 2030 , and the system has been credited with the lifetime remaining after 2030. Each system is designed to supply $90 \%$ renewable energy (the remaining 10\% covered by the diesel back-up) to cover an expected daily demand of $200 \mathrm{kWh}$ per system (Government of Kenya, 2018; REA, 2016). Customer categories include households, businesses and local institutions. For this purpose, the ratio of businesses/households characterizing the K-OSAP mini-grids has been used and businesses and local institutions are therefore assumed to account for $23 \%$ of all customers.

Lastly, we have chosen only to focus on the direct effects of the introduction of the mini-grids in regards to the environmental impacts, and not take into consideration the possible changes in household consumption patterns resulting from an improved access to electricity. A complete list of assumptions made for the baseline and policy scenarios can be found in the Supplementary Material.

\section{Results}

This section presents the results for the assessed impact categories. The most relevant impact categories are explained in detail, while results for other impact categories are briefly mentioned in a separate section.

\subsection{Environmental impact}

\subsubsection{Climate change mitigation}

The policy scenario is found to perform significantly better than the baseline scenario with regard to GHG emissions, reducing the original impact by $71 \%$, equivalent to a net impact of emission reductions of around $4900 \mathrm{tCO}_{2} \mathrm{eq}$ peryear and $34,000 \mathrm{tCO}_{2}$ eq for the full assessment period, as reported in Table 1. For the baseline scenario, the main contributor to climate change is found to be the combustion of kerosene, which accounts for $78 \%$ of the baseline impact, while the burning of diesel in the diesel generator and the production of solar panels are the main contributors to climate change in the policy scenario, accounting for $43 \%$ and $36 \%$ of the impact respectively.

\subsubsection{Air pollution}

The policy is expected to lower emissions of particulate matter compared to the baseline scenario by $96 \%$, corresponding to a reduction of 592 DALYs. ${ }^{2}$ The results for the baseline and policy scenarios are presented in Table 1. Of the overall impact reduction, $95 \%$ is estimated to come from the reduced use of kerosene for lighting, primarily impacting indoor environments. Indoor air pollution, especially from kerosene, has been reported to kill more people than AIDS and Malaria combined (WHO, 2018a). However, these estimates focused on emissions from cooking, and not from lighting, which produces considerably less emissions. Considering the population under assessment, this result corresponds to 7 hours of DALY per person per year. Even if this number might look quite small, it should be noted that the impact in reality will not be homogeneously distributed and that, especially women and children, might be affected more (UNDP, 2012).

\subsubsection{Other environmental impacts}

Waste generation impacting local communities is found to be affected negatively in the policy scenario by a possible major increase in e-waste from solar PV modules and batteries from mini-grids, due to the lack of a nationwide formal collection network (Magalini et al., 2016). At the same time, as consumption of the traditional 
sources of light will decline, the production of waste connected with the use of dry-cell batteries and SHS, which often gets disposed in an improper manner (Lenz et al., 2017), will be reduced, bringing moderate positive impacts. Depletion of non-renewable resources has been assessed through two sub-categories, fossil fuel resources and mineral resources. The LCA results from fossil fuel resource depletion reveal improvements in this category. Resource depletion is quantified as a future cost due to lower availability of the resource, and the policy scenario entails a decrease in the impact of 5.2 million $U_{S D}^{3}$ on fossil fuel resources over the assessment period. For mineral resource depletion, the policy scenario will bring a $3 \%$ increase in the impact compared to the baseline, provided that the discarded Li-ion batteries from the mini-grid are recycled, corresponding to 720 USD over seven years. In terms of human toxicity, the policy scenario performs better than the baseline, halving the impact of the scenario without electricity, but bringing only a minor positive impact of 5 DALYs. A summary of the LCA results on the selected impact categories is provided in Table 1.

Table 1. Summary of LCA results on the selected impact categories.

\begin{tabular}{|c|c|c|c|c|c|}
\hline Impact category & Indicator & $\begin{array}{l}\text { Baseline } \\
\text { Scenario } \\
\text { (1 year) }\end{array}$ & $\begin{array}{l}\text { Policy } \\
\text { scenario } \\
\text { (1 year) }\end{array}$ & $\begin{array}{l}\text { Net impact } \\
\text { (1 year) }\end{array}$ & $\begin{array}{l}\text { Net impact } \\
(2024-2030)\end{array}$ \\
\hline $\begin{array}{ll}\text { Climate } & \text { Change } \\
\text { mitigation } & \end{array}$ & $\begin{array}{l}\text { GHG emissions } \\
\text { [t } \mathrm{CO}_{2} \text { eq.] }\end{array}$ & 6,900 & 2,000 & $-4,900$ & $-34,000$ \\
\hline Air pollution & $\begin{array}{l}\text { Particulate matter } \\
\text { [DALY] }\end{array}$ & 88 & 3 & -85 & -592 \\
\hline Human Toxicity & $\begin{array}{l}\text { Human carcinogenic \& non- } \\
\text { carcinogenic toxicity } \\
\text { [DALY] }\end{array}$ & 2.2 & 1.5 & -0.7 & -5 \\
\hline \multirow[t]{2}{*}{$\begin{array}{l}\text { Depletion of non- } \\
\text { renewable resources }\end{array}$} & $\begin{array}{l}\text { Mineral resource depletion } \\
\text { [USD] }\end{array}$ & 3,300 & 3,400 & +100 & +720 \\
\hline & $\begin{array}{l}\text { Fossil resource depletion } \\
\text { [USD] }\end{array}$ & 960,000 & 210,000 & $-750,000$ & $-5,200,000$ \\
\hline
\end{tabular}




\subsection{Social impact}

\subsubsection{Access to clean, reliable and affordable energy}

Even though all households and businesses assessed will have access to the mini-grid, there might be households who will not be able to afford a potential connection fee and thus remain unconnected. Nevertheless, a specific impact on access to electricity is very likely to be achieved by the policy and the magnitude of the impact will be major. Access to a clean source of cooking could also be affected by the access to electricity but here, the link is tangential. Cleaner cooking from electricity can be achieved primarily through the substitution of biomass with electric stoves (SE4All, 2013) or through smaller appliances like rice cookers. However, the cost of buying electric stoves represents a burden for the majority of the customers (World Bank, 2008), and these are projected to supply only $15-20 \%$ of the cooking in developing countries in 2030 (International Energy Agency, 2017). Overall, given the uncertainties, this specific impact is assessed as possible and minor.

\subsubsection{Accessibility and quality of education}

Improved access to education was identified as one of the most important and potentially most affected categories by the majority of the stakeholders. The most significant specific impact for education is found to be the increase in quality of education facilities and teaching. This impact has been reported both through improved learning equipment in the schools, such as tools for science laboratories, computers and photocopying machines, or other electric appliances allowing the teaching of technical subjects, and through improved staff retention and teacher performance (Azimoh, Klintenberg, Mbohwa, \& Wallin, 2017; Kirubi, Jacobson, Kammen, \& Mills, 2009; Riva, Ahlborg, Hartvigsson, Pachauri, \& Colombo, 2018; UNDESA, 2014). An increase in the quality of education facilities and teaching has therefore been scored as likely and moderate.

Even though electricity is often believed to be connected with extended study hours at home and school, we have found contradicting evidence on this matter. In fact, if it is true that evening study increases (Harrison et al., 2016; Kirubi et al., 2009; UNDESA, 2014; World Bank, 2008), the absolute change is not significant, and the study time simply shifts from day to night time (Lenz et al., 2017). An impact on extended study hours at home and school has been assessed as likely and minor. Finally, the last specific impact considered is higher attendance and school performance. Electricity is often associated with a small increase in school attendance (Khandker, Samad, Ali, \& Barnes, 2012; Lipscomb, Mobarak, \& Barham, 2013; Van de Walle, Ravallion, Mendiratta, \& Koolwal, 2013; World Bank, 2008). However, a few studies report school attendance and performance not to increase, at least in the short term (Azimoh et al., 2017; Lenz et al., 2017). An impact on this category has been assessed as possible and minor.

\subsubsection{Accessibility and quality of healthcare}

Health centres may benefit from access to electricity in different ways. Clinics with access to electricity are reported to be open for longer hours, compared to the ones without access (World Bank, 2008). Moreover, electricity can also improve outcomes for childbirth, surgery and other medical interventions, and can enable operations at night, maximize use of medical machines, and facilitate administrative tasks (Azimoh et al., 2017; Lenz et al., 2017; Riva et al., 2018). As reported by Lenz et al. (2017), this improvement in healthcare facilities can further attract staff from urban areas. Altogether, mini-grids contribute to enhancing the quality and accessibility of local health centres, bringing likely and moderate positive impacts.

Additionally, preserving vaccines is reported as one of the biggest impacts brought about by access to electricity (Azimoh et al., 2017; Riva et al., 2018; World Bank, 2008), especially considering the better reliability of mini-grids compared to the national grid (Winther, Ulsrud, \& Saini, 2018). This specific impact has been assessed as likely, with moderate consequences.

\subsubsection{Other social impacts}

In the other analyzed social impact categories, we found gender equality and empowerment of women to be affected positively with likely and moderate impacts mainly through improvements for women's mobility at night (Azimoh et al., 2017; World Bank, n.d.) and with possible and minor impact through enhanced womeńs knowledge on health and family planning through access to information (World Bank, 2008). During the interviews, stakeholders expressed strong expectations with regard to the effect of the mini-grids on food security, especially through increased agricultural productivity, and access to water. However, agricultural productivity and water access have been assessed as unlikely to be affected, since no causality has been demonstrated in the studies reporting impacts 
of electricity access in rural communities. This is most probably due to the fact that the mini-grids are not meant to provide electricity for agricultural activities, and that other systems (e.g. solar water pumps) should be put in place. Nevertheless, both stakeholder interviews and the literature report likely positive and minor impacts on agricultural productivity and food storage through improved knowledge, derived from access to information from either TV or mobile phone use (Jacobson, 2007). Moreover, the ability to store food in refrigerators might also be affected by the access to electricity, bringing likely and moderate impacts (Azimoh et al., 2017; Kirubi et al., 2009; Willcox et al., 2015).

\subsection{Economic impact}

\subsubsection{Economic activity in the community}

Limited power supply represents a major constraint, especially for small and medium-sized enterprises in SubSaharan Africa (CDC Group, 2016). The introduction of mini-grids is therefore expected to have a positive impact on the economic activity of the community.

Business creation is largely claimed as one of the main outcomes of electricity access, and was also reported by one stakeholder involved in a mini-grid project (Willcox et al., 2015). However, recent studies reportcreation of businesses due to electricity access to be minor or insignificant, at least in the short term (Lenz et al., 2017; Pueyo \& DeMartino, 2018). An exception is businesses offering services connected with electricity, which show major increases (Pueyo \& DeMartino, 2018). Impacts on creation of businesses have been assessed as likely to happen and bring, based on the study above, moderate impacts.

Similarly, although studies report an important increase in productivity after mini-grid deployment (Kirubi et al., 2009), most of the papers reporting effects of electricity on economic activities lack the use of a consistent methodology and do not report quantitative results (Riva et al., 2018). Two recent studies by (Lenz et al., 2017; Pueyo \& DeMartino, 2018) conclude that rural electrification has not had the intended effect of improving business performance. Access to markets and finance, infrastructure such as roads, telecommunications, water systems, or complementary activities to promote the productive use of electricity, are essential for achieving a high impact on production (Cook, 2011; Prasad, 2008; Riva et al., 2018). Therefore, although it enables these impacts, electricity is a necessary but not sufficient precondition for income generating activities (Bhattacharyya \& Palit, 2016; Pueyo \& DeMartino, 2018). Considering that the REA and KPLC will also promote productive and efficient use of energy by users (Kenya Power \& REA, 2017), the impacts on increased productivity have been considered likely and minor, also taking into account that some of the wealthier households and businesses might already have SHS or diesel generators in place. An additional impact, which electrification would very likely lead to, is access to finance through mobile phones (Kirubi et al., 2009; Winther et al., 2018). However, although access to finance might contribute significantly to improved economic activity, the fact that the use of phones for this purpose is already common means this impactis considered minor (Winther etal., 2018).

\subsubsection{Other economic impacts}

Another expected impact is job creation in the power sector, for which the deployment of the mini-grids could bring positive impacts both inside and outside the Kenyan context. Juchau and Solan (2013) report solar PV to be the technology with the highest number of jobs per average MW produced, considering construction, installation, manufacturing, operation and maintenance. The impact on this specific category has been assessed as likely and moderate. At the same time, a decrease in the use of traditional sources of light might lead to negative effects in terms of employment in the respective sectors. However, due to the lack of data on this matter, it was not possible to determine the magnitude and likelihood of this specific impact.

An increase in economic activity in the community will likely bring other economic impacts, especially in terms of employment and income. In a context where the only employees are normally the owner and unpaid family members, minor and likely impacts are expected to be seen and have been reported both by stakeholder interviews and existing literature (CDC Group, 2016; Kirubi et al., 2009; Lenz et al., 2017; Pueyo \& DeMartino, 2018; Riva et al., 2018; Willcox et al., 2015; World Bank et al., 2017).

As for the impacts on income, studies report moderate and sometimes major increases in income for businesses and households (Jacobson, 2007; Kirubi et al., 2009; Willcox et al., 2015). However, as for the impact category 'economic activity', this impact is dependent on the socio-economic preconditions prevailing in the community (Lenz et al., 2017; Pueyo \& DeMartino, 2018). In the absence of these conditions, the impacts are found to be minor or statistically insignificant, and sometimes studies do not provide statistically reliable estimates and a clear baseline (Pueyo \& DeMartino, 2018; Riva et al., 2018). The pathway through which electricity access would bring an increase in income is considered to be possible and the impacts arising from it are expected to be moderate.

All these impacts, if enabled, could ultimately bring about an increase in GDP. Indeed, data shows that electricity 
consumption and economic growth go hand in hand (CDC Group, 2016; Faisal \& Resatoglu, 2016; Jumbe, 2004; Shiu \& Lam, 2004; Stern, Burke, \& Bruns, 2017; Wolde-Rufael, 2006). However, although there is a linear correlation between the two, there is disagreement on which one drives the other (ibid.). An increase in GDP in the long run has therefore been assessed as possible and moderate, considering the moderate electricity consumption level provided.

Finally, deployment of the mini-grids is likely to bring cost savings compared to the baseline scenario. Monthly expenses in rural Kenya for kerosene, candles, batteries, mobile charging, diesel generators ${ }^{4}$ and SHS are estimated to be around 10.10-13.55 USD (Carbon Africa Limited et al., 2015; Pueyo\& DeMartino, 2018; Rom et al., 2017; Van Acker et al., 2014). On the other hand, mini-grid domestic customers and small businesses paying the KPLC tariffs, which depend on the level of consumption, are expected to pay somewhere between 1.76 USD and 10.90 USD per month, considering an expected demand of 10 and $50 \mathrm{kWh} /$ month per customers, respectively (REA, 2016).

\subsection{Contribution to SDGs}

Before moving on to the discussion, this section will briefly outline the linkages between the assessed impacts and the SDGs. Impact categories and specific impacts have been connected to the relevant SDG targets follow- ing the steps outlined in the SDG impact methodology section. The links between the broader impact categories and the SDG targets are outlined in Table 2. A more detailed list, including the specific impact and the reasoning behind the linkages, can be found in Table 12 in the Supplementary Material.

Based on the environmental, social and economic impacts described in the previous sections, Figure 3 reports the impacts on the SDG targets using the colour coding outlined in the methods section. As revealed by this representation, the policy is found to impact numerous SDGs, beyond climate action (SDG13) and afford- able and clean energy (SDG7).

Table 2. Links between impact categories and SDGs.

\begin{tabular}{lll}
\hline Impactcategory & \multicolumn{1}{c}{ SDG } & SDG targets \\
\hline Climate Change mitigation & 9 Industry, Innovation, and Infrastructure, 13 Climate action & $9.4,13.2$ \\
Air pollution (Indoor and Outdoor) & 3 Good health and well-being, 11 Sustainable cities and communities & $3.9,11.6$ \\
Human Toxicity (Air, water and soil) & 3 Good health and well-being & 3.9 \\
Depletion of non-renewable resources & 12 Responsible consumption and production & 12.2 \\
Waste generation and disposal & 12 Responsible consumption and production & $12.4,12.5$ \\
Accessibility and quality of health care & 3 Good health and well-being & $3.8,3 . b$ \\
Food security & 2 Zero hunger & 2.3 \\
Access to safe drinking water & 6 Clean water and sanitation & 6.1 \\
Access to clean, reliable and affordable energy & 7 Affordable and clean energy & $7.1,7.2,7 . b$ \\
Accessibility and quality of education & 4 Quality education & $4.1,4.6,4 . a, 4 . c$ \\
Gender equality and empowerment of women & 5 Gender equality, 11 Sustainable cities and communities & $5.6,11.7$ \\
Economic activity at community level & 8, 1 No poverty & $8.3,1.4$ \\
Employment & 8 Decent work and economic growth & 8.5 \\
Expenses for electricity & No links have been found & - \\
Income & 10 Reducing inequalities & 10.1 \\
Economic growth & 8 Decent work and economic growth & 8.1 \\
\hline
\end{tabular}

\begin{tabular}{|c|c|c|c|c|c|}
\hline 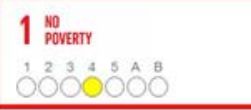 & Math & 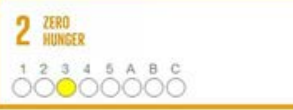 & 巛I & 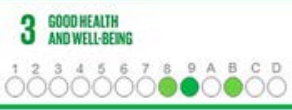 & $-w$ \\
\hline 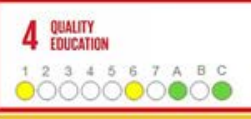 & أل1 & 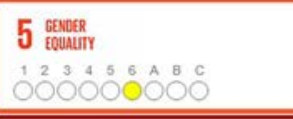 & $\Theta_{+}^{n}$ & 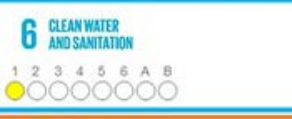 & 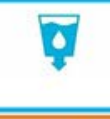 \\
\hline 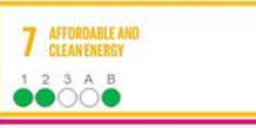 & 涿 & 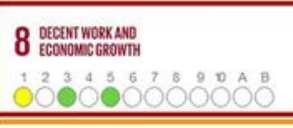 & 行 & 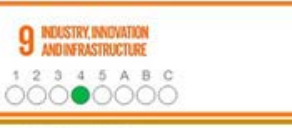 & 8 \\
\hline 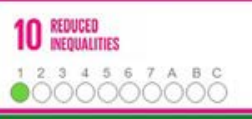 & 言 & 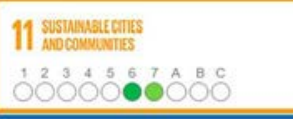 & 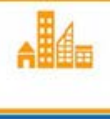 & 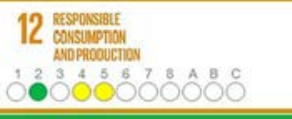 & O० \\
\hline 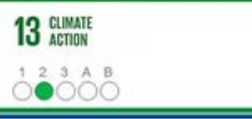 & (8) & 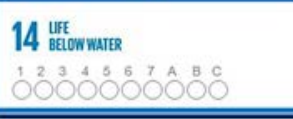 & $\tilde{\tilde{O}}$ & 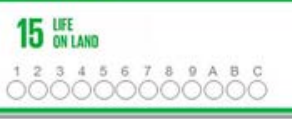 & $\stackrel{=}{=}$ \\
\hline 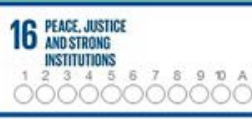 & $y_{1}^{\prime \prime}$ & 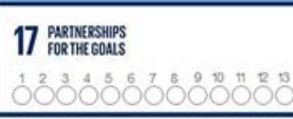 & 8 & & 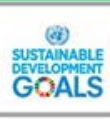 \\
\hline
\end{tabular}

- Very negativeimpact Negative impact $\bigcirc$ Not assessed Uncertain/insignificant impact Positive impact Very positiveimpact 
Figure 3. Impacts on the SDGs targets. The circles in the SDG boxes represent the 169SDG targets. The colour of the frames represent the colour of the SDGs.

\section{Discussion}

We now turn to discuss the results of the study in the context of the climate and development linkages debate, and analyze how these findings can be used by decision-makers. We then discuss the possibility of applying the approach presented in this paper to assess full NDCs. Finally, we present some considerations on the adopted methodology.

\subsection{Kenya's NDC and the SDGs in the case of mini-grids: synergies and trade-offs}

Kenya's NDC aims to reduce GHG emissions from electricity generation by $9.32 \mathrm{MtCO}_{2} \mathrm{eq}$ by 2030 . The mini-grid policy, even though it is expected to lower GHG emissions by $71 \%$ compared to the scenario in which villages are unconnected, only contributes to achieving $0.4 \%$ of the current NDC target for the power sector. Although this result appears small, it is in line with the size of the analyzed systems, which cover roughly $0.4 \%$ of the $2405 \mathrm{MW}$ of new power capacity expected to be deployed. Considering the potential market for mini-grids, based on a cost-optimal approach for 4.95 million people (10\% of the population) (Moksnes, Korkovelos, Mentis, \& Howells, 2017), the solar PV mini-grids analyzed in this report could contribute to a GHG emission reduction of $1.34 \mathrm{MtCO}_{2} \mathrm{eq}$ by 2030.

As the results on the broader environmental, social and economic impact categories reveal, the introduction of the mini-grids will impact much more than just the climate. Twenty-five targets under 13 SDGs have been found to be linked to the impacts that have been assessed. Sixteen targets are positively affected by the action considered, and for eight targets, the impact is either uncertain or not significant. Positive impacts are expected on the targets of SDG 3 (health), 4 (education), 7 (energy), 8 (work), 9 (industry innovation), 10 (inequalities), 11 (sustainable cities), 12 (consumption and production), and 13 (climate). Meanwhile, negative impacts may also arise. In the environmental pillar, negative impacts might arise for SDG targets 12.4 (achieve the environmentally sound management of chemicals and wastes) and 12.5 (reduce waste generation), due to e-waste from the mini-grids. However, this is balanced by likely reduction of waste from batteries and kerosene in the baseline scenario, making the impact on these targets unclear. Minor negative impacts have also been found with regard to mineral resource depletion, connected with SDG target 12.2. However, the indicator used for mineral resource depletion in this LCA is based on the amount of minerals available in the upper crust of the earth that is ultimately recoverable. For the model used, this value corresponds to $0.01 \%$ of the total amount of a mineral available in the crust up to a depth of $3 \mathrm{~km}$ (Huijbregts et al., 2016). Even though the policy entails a small increase in the use of mineral resources, there are doubts over whether mineral resources are a real issue when it comes to sustainability (Chen, 2011; Schmidt, 2019). This uncertainty results in most of the indicators for mineral resource depletion still lacking a sufficient level of scientific quality to be used for recommendations (Hauschild etal., 2013). The small impacts on mineral resources are outweighed by the positive contribution to fossil fuel resource depletion, which also impacts the same target (depletion of non-renewable resources). Other impacts, which have not been reported in the paper because they were found not significant or not relevant, arise from terrestrial, freshwater and marine ecotoxicity connected to SDG 14.1 and 15.5. These categories could see some negative impacts, although not significant ones.

\subsection{Cost of $\mathrm{CO}_{2}$ abatement}

Economically, the establishment of mini-grids requires investment. For the K-OSAP mini-grids analyzed in this study, the investment is estimated to be 20 million USD (World Bank, 2017). Using the GACMO tool, ${ }^{5}$ and considering the GHG emission reductions that the K-OSAP mini-grids will bring, the cost of $\mathrm{CO}_{2}$ abatement for this technology is found to be $107 \mathrm{USD} / \mathrm{tCO}_{2}$ eq (calculations can be found in Table 13 in the Supplementary Material). Comparing this result with the GHG abatement costs of other technologies reported in the GACMO Tool, this cost appears high compared to most of the other measures, but lower compared to the abatement cost for solar-diesel mini-grids reported by the tool ( $\left.117 \mathrm{USD} / \mathrm{tCO}_{2} \mathrm{eq}\right)$. One reason for this is that the baseline for this technology is no access to electricity, which does not entail any investment or maintenance cost, but only the expenses for the customers. Although the cost for the customers is lower compared to the baseline scenario, the huge economic investment outweighs these savings. In fact, the mini-grid intervention, in this context, aims at providing access to electricity, rather than only abating GHG emissions.

\subsection{Policy reflections}

Kenya has set ambitious goals for electrification with the aim of achieving universal access by 2020 . This target calls 
for accelerated implementation particularly in the most remote, rural areas, often home to the poorest households. While the intervention assessed in this paper will result in a $0.2 \%$ increase in the electrification rate, $30 \%$ of the population is still without access to electricity (Government of Kenya, 2018). The question of how to scale up minigrid implementation is thus highly relevant. Private sector engagement to leverage private finance is highlighted as an important contributor to achieving such scale up (Schmidt, Blum, \& Sryantoro Wakeling, 2013; Williams, Jaramillo, Taneja, \& Ustun, 2015), in which a private developer invests in the generation of power and sells power to KPLC as the sole counterparty to its Power Purchasing Agreement (PPA). The Government of Kenya funds distribution assets and KPLC will be responsible for distribution and retail of power to customers at its uniform national tariff (Nygaard et al., 2018). KPLC will purchase electricity at a higher cost than it can sell to the customers and a crosssubsidy within the KPLC customer base is applicable to compensate for the losses incurred (ibid). While this model is used within the traditional public bodies like REA and KPLC it is criticized by private actors for notharnessing the full potential of private sector investments. While purely private models, in which private mini-grid developers rely on private equity and commercial loans to electrify rural villages, exist these models face various policy barriers to upscaling. Although the Kenyan electricity market has been liberalized and opened up to private sector involvement (Kapika \& Eberhard, 2013), the current regulatory and policy frameworks are not conducive to private mini-grid development (Pedersen \& Nygaard, 2018). Lack of clear policies on options for grid-integration in cases where the national grid arrives at a privately operated site, as well as a national uniform tariff level, are some of the main barriers facing private mini-grid developers. Private firms are demonstrating the ability to deliver lower cost solutions at the system level compared to conventional grid extension. However, the tariffs charged to their customers through the private models reflect actual costs and are thus not on a par with the cross-subsidized national tariff. Public investments in infrastructure and redistribution of revenues from urban to rural settings will be a key instrument in any effort to achieve universal electrification. While cross-subsidies within the current public electrification regime is common practice, it is highly relevant to consider how private actors could or should get access to similar public subsidies in order to deliver power at the same price level as the national tariff.

The results of the current analysis show that implementation of mini-grids is not only contributing towards the primary goals of electrification and GHG emission reductions, but also to a broad set of positive sustainable development impacts such as on health, education and other areas. This additional contribution to multiple SDGs, beyond what is primarily seen as an energy and climate change intervention, is a solid argument for increasing support for accelerated, more ambitious climate policies and targets. It also testifies to the value of performing a broader sustainability assessment of alternative climate mitigation policy actions. The assessment of the sustainable development impacts of climate policies and actions responds to the call to break down silos in policy making to enhance potential synergies across sectors and ministries (Fuso Nerini et al., 2018).

\subsection{From individual NDC actions to full NDCs}

Our analysis has assessed the mitigation component of the Kenyan NDC as positively impacting nine SDGs. However, NDCs sometimes enhance, and sometimes come at the expense of, other SDGs (lyer et al., 2018). The approach that has been applied here could also be used to evaluate the overall impact of an NDC, by summing up impacts of individual projects, revealing, in this way, the overall synergies and trade-offs of a full NDC. While the results presented in this paper have found the mini-grid policy to be linked to 25 targets out of 169, an analysis of the overall Kenyan NDC would unveil a much higher and more wide-reaching impact on the SDGs in terms of targets affected, both positively and negatively. According to the literature, energy policies on their own could potentially drive impacts on 143 SDG targets, with twice as many synergies as trade-offs (Fuso Nerini etal., 2018). Assessing the impact of the full NDC on the SDGs could provide science-based decision-support to policymakers seeking to evaluate which other sustainable development objectives are affected positively or negatively by national climate policies and actions, and help identify the most attractive ones. Furthermore, accounting for the total sustainable developmentimpacts of an NDC programmewould support a more relevant and true balancing of its benefits and costs (lyer et al., 2018).

However, aggregating the impacts of multiple single project assessments is challenging. Quantitative data for indicators can be summed up, provided that the data express the same kind of impact, with the same metrics, and using the same time of reference. For qualitative impacts, the situation is more complex. Qualitative impacts presented in this paper are assessed relative to the local conditions or to the maximum potential impact from policy options, which means that the magnitude of the impact depends on the scale of the assessment. This entails that qualitative impacts assessed from projects at different scales need to be re-evaluated using the same broader conditions as a reference, before they can be aggregated. 


\subsection{Additional considerations and limitations of the assessment}

The analysis performed is in line with the approach outlined in the decision on Modalities, Procedures and Guidance to track impacts of NDCs adopted as part of the 2018 Katowice Climate Package (UNFCCC, 2019), which compares a scenario with measures (e.g. the introduction of mini-grids), to a scenario without measures (e.g. no electricity). However, it is likely that, in reality, deviations from the baseline and policy scenarios may occur. In this section, we identify some of the impacts that may not be captured in this analysis, which follows a rather static perspective.

Additional negative environmental impacts might arise in the longer term related to the expected positive societal impacts of increased GDP, increased living standards and resulting increased consumption of goods. However, since an increase in GDP deriving from access to electricity has been considered only possible and of moderate consequence, such implications for households' consumption of goods are even more unclear. At the same time, there could be positive effects due to a change in perception towards renewables. Such a wide national intervention could, in fact, further familiarize the population with renewable energy, resulting in an exponential adoption of similar technologies, helping in this way to avoid carbon lock-in (Schwerhoff \& Sy, 2019; Unruh, 2002). Finally, deviations may occur in the policy scenario, connected to the operation of the mini-grids, which have been considered to work as per their design. For instance, challenges may be encountered during the implementation and operation of a mini-grid (e.g. abandonment of the project), which could compromise its operations, and therefore, its impact on sustainable development.

\subsection{ICAT sustainable development guidance: benefits and challenges}

Tools such as the ICAT Sustainable Development Methodology have strategic potential for raising climate action ambition. The assessment looks at both positive and negative impacts, belonging to the three pillars of sustainability. The approach used to ensure this comprehensive coverage of impact categories, included a variety of sources, such as literature on rural electrification, policy, country, and global development objectives, LCA databases (Ecoinvent), and stakeholder interviews. Although the number of stakeholders interviewed was rather limited, this step was important to enhance the validity of the ICAT Sustainable Development Methodology and ground the results with a 'reality check'.

Regarding the methodology for our study, we have identified three limitations relating to a general lack of data, methodological aspects, and case study aspects. Lack of data is a challenge that most developing countries face when applying ICAT guidance. In the Kenya case study, only a few studies are available reporting reliable results on sustainable development impacts for mini-grids in Kenya. The qualitative impact assessment comes very handy in this sense, since it does not require much data. At the same time, it has the drawback that the evaluation may become more subjective, particularly when empirical evidence is scarce. Moreover, the lack of literature on the long-term impacts of rural electrification in developing countries makes the analysis of possible long-term impacts on education, economic activity and livelihoods in general, very uncertain. By using tools such as the ICAT Sustainable Development Methodology, governments can identify where more data is needed, either because impacts are deemed important or because there is a fundamental lack of data in a specific area. In this way, data collection for national monitoring, reporting and verification (MRV) systems for integrated GHG and sustainable development assessment can be strengthened.

\section{Conclusion}

Future NDCs are expected to include a discussion of relationships between mitigation and other societal goals (lyer et al., 2018). Analyzing the expected contribution of NDCs to globally accepted and well-known development goals such as the SDGs, can give leverage to policymakers to justify more ambitious climate actions and ensure more comprehensive, well-designed policies.

Taking Kenya's NDC as a case study, and focusing on the national plan for increasing electricity access in rural areas through solar PV mini-grids, we have used the ICAT Sustainable Development Methodology to show how synergies and trade-offs between NDCs and SDGs can be assessed. The deployment of the

146 mini-grids considered is expected to lower GHG emissions by $71 \%$ compared to the scenario in which villages are unconnected; however, it only contributes to $0.4 \%$ of the current NDC target for the power sector. This GHG emission reduction is in line with the size of the systems analyzed. Although the deployment of the mini-grids will have important climate benefits, the considerable economic investment required makes it a relatively expensive solution, compared to other mitigation technologies, in terms of $\mathrm{CO}_{2}$ abatement cost. ${ }^{6}$ However, the analysis of the broader environmental, social and economic impact categories reveals that the introduction of the mini-grids will generate substantial benefits beyond GHG reductions. Apart from providing access to electricity, which is in itself a positive impact, the mini-grid policy will enable a series of co-benefits 
including reduction of indoor air pollution, access to and improved quality of healthcare, improved quality of education and increased economic activity. These are in turn found to positively affect 16 SDG targets under the 2030 Agenda including targets of SDGs 3, 4, 7, 8, 9, 10,11, and 12. Nevertheless, real progress on some of these categories highly depends on complementary activities, which support the productive use of electricity. Apart from the economic investment required, possible negative impacts are associated with the electronic waste generated at the end of life of the mini-grid and small impacts on mineral resource depletion. Increased consumption of goods from households due to better economic conditions in the long run could also bring additional negative environmental impacts, as well as positive social impacts. These long-term impacts deriving from an increased consumption of goods, however, have not been analyzed in this paper, which had the purpose to compare the mini-grid deployment with the current situation on an equal functional basis.

Tools such as the ICAT Sustainability Assessment Methodology can account for the impacts on broader societal and environmental goals, and in this way better account for the costs and benefits of policies. Showing that, for example in our case, implementation of mini-grids is not contributing only to GHG reduction and electrification could act as an argument for increasing broader support for climate action among policymakers and in this way raise the ambition of policies. Furthermore, this kind of assessment can be useful in policy design and implementation to ensure that synergies are maximized and trade-offs are minimized.

\section{Notes}

1. The tariffs used for the calculation of the electricity costs have been retrieved from https://stima.regulusweb.com/.

2. DALYs: Disability Adjusted Life Years. This measure expresses the lost years of healthy life calculated summing the Years of Life Lost (YLL) due to premature mortality, and the Years Lost due to Disability (YLD) (WHO \& Metrics: Disability-Adjusted Life Year, 2018b).

3. Impacts on mineral and fossil fuel resource depletion are expressed as surplus cost, which is defined as the total additional future cost to society due to the production of one unit of resource (Huijbregts et al., 2016; Ponsioen, 2013).

4. The price per litre of diesel for Kenya has been retrieved from GlobalPetrolPrices.com.

5. GACMO is a tool developed by UNEP-DTU Partnership to analyse GHG mitigation options for a country or region (available at cdmpipeline.org).

6. Considering only the mini-grids belonging to the K-OSAP programme.

\section{Disclosure statement}

No potential conflict of interest was reported by the authors.

\section{References}

Azimoh, C. L., Klintenberg, P., Mbohwa, C., \& Wallin, F. (2017). Replicability and scalability of mini-grid solution to rural electrification programs in sub-Saharan Africa. Renewable Energy, 106, 222-231. doi:10.1016/j.renene.2017.01.017

Bacon, R., Bhattacharya, S., \& Kojima, M. (2010). Expenditure of low-income households on energy evidence from Africa and Asia. Retrieved from www.worldbank.org/ogmc

Bhattacharyya, S. C., \& Palit, D. (2016). Mini-grid based off-grid electrification to enhance electricity access in developing countries: What policies may be required? Energy Policy, 94, 166-178. doi:10.1016/j.enpol.2016.04.010

Blodgett, C., Moder, E., Kickham, L., \& Leaf, H. (2016). Powering productivity. Early insights into mini grid operations in rural Kenya. Retrieved from http://www.vulcan.com/MediaLibraries/Vulcan/Documents/Kenya-Mini-Grids-White-Paper-VI2.pdf

Carbon Africa Limited, Trama TecnoAmbiental S.L., Research Solutions Africa Limited, \& Energy research Centre of the Netherland. (2015). Kenya market assessment for off-grid electrification final report. Retrieved from http://www.renewableenergy.go.ke/asset_uplds/files/ERCIFCmini-grids-final report-Final.pdf

CDC Group. (2016). What are the links between power, economic growth and job creation? Retrieved from http://www.cdcgroup.com/Documents/Evaluations/Powereconomicgrowthandjobs.pdf

Chen, Z. (2011). Global rare earth resources and scenarios of future rare earth industry. Journal of Rare Earths, 29(1), 1-6. doi:10.1016/S1002-0721(10)60401-2

Cook, P. (2011). Infrastructure, rural electrification and development. Energy for Sustainable Development, 15(3), 304-313. doi:10.1016/j.esd.2011.07.008

Eales, A., Walley, L., Buckland, H., Frame, D., \& Strachan, S. (2018). Social impacts of mini-grids: Towards an evaluation methodology. Power Africa. doi:10.1109/PowerAfrica.2018.8521049

Economic Consulting Associates, Trama Tecno Ambiental, \& Access Energy. (2014). Project design study on the renewable energy development for off-grid power supply in rural regions of Kenya project. Retrieved from http://www.renewableenergy.go.ke/asset_uplds/files/ECAKenyaMinigridsReport-revisedfinal(1).pdf

Faisal, T., \& Resatoglu, N. G. (2016). Energy consumption, electricity, and GDP causality; The case of Russia, 1990-2011. Procedia Economics and Finance, 39, 653-659. doi:10.1016/S2212-5671(16)30312-4

Fuso Nerini, F., Tomei, J., To, L. S., Bisaga, I., Parikh, P., Black, M., ... Mulugetta, Y. (2018). Mapping synergies and trade-offs between energy and the sustainable development goals. Nature Energy, 3(1), 10-15. doi:10.1038/s41560-017-0036-5

German Development Institute / Deutsches Institut für Entwicklungspolitik (DIE), \& Stockholm Environment Institute (SEI). (2019). NDC- SDG connections: Bridging climate and the 2030 agenda. Retrieved from https://klimalog.die-gdi.de/ndc-sdg/country/Low_Income 
Government of Kenya. (2013). National Climate Change Action Plan 2013 -2017.

Government of Kenya. (2018). National Climate Change Action Plan (Kenya): 2018-2022. Volume 3: Mitigation Technical Analysis Report. Nairobi: Ministry of Environment and Forestry. Retrieved from http://www.Ise.ac.uk/Granthamlnstitute/wpcontent/uploads/2018/10/8737_vol3.pdf

Harrison, K., Scott, A., \& Hogarth, R. (2016). Accelerating access to electricity in Africa with off-grid solar the impact of solar household solutions. Retrieved from https://www.odi.org/sites/odi.org.uk/files/odi-assets/publications-opinion-files/10229.pdf

Hauschild, M. Z., Goedkoop, M., Guinée, J., Heijungs, R., Huijbregts, M., Jolliet, O., ... Pant, R. (2013). Identifying bestexisting practice for characterization modeling in life cycle impact assessment. The International Journal of Life Cycle Assessment, 18(3), 683-697. doi:10.1007/s11367-012-0489-5

Huijbregts, M., Steinmann, Z. J. N., Elshout, P. M. F. M., Stam, G., Verones, F., Vieira, M. D. M., ...van Zelm, R. (2016). ReCiPe 2016: A harmonised life cycle impact assessment method at midpoint and endpoint level. Report I: Characterization, 194. https://doi.org/10.1007/s11367-016-1246-y

ICAT. (2018). Sustainable development guidance. Guidance for assessing the environmental, social and economic impacts of policies and actions. May 2018 Version. Initiative for Climate Action Transparency (ICAT), World Resources Institute and UNEP DTU Partnership, Editors: Rich D \& Olsen KH, Washington DC, US and Copenhagen, Denmark.

International Energy Agency. (2017). WEO-2017 special report: Energy access outlook. Retrieved from https://www.iea.org/ publications/freepublications/publication/WEO2017SpecialReport_EnergyAccessOutlook.pdf

Iyer, G., Calvin, K., Clarke, L., Edmonds, J., Hultman, N., Hartin, C., ... Pizer, W. (2018). Implications of sustainable development considerations for comparability across nationally determined contributions. Nature Climate Change, 8(2), 124-129. doi:10.1038/s41558- 017-0039-z

Jacobson, A. (2007). Connective power: Solar electrification and social change in Kenya. World Development, 35(1), 144-162.

doi:10.1016/j.worlddev.2006.10.001

Juchau, C., \& Solan, D. (2013). Employment estimates in the energy sector: Concepts, methods, and results. The Energy Policy Institute (March).

Jumbe, C. B. (2004). Cointegration and causality between electricity consumption and GDP: Empirical evidence from Malawi. Energy Economics, 26(1), 61-68. doi:10.1016/S0140-9883(03)00058-6

Kapika, J., \& Eberhard, A. (2013). Power-sector reform and regulation in Africa: Lessons from Kenya, Tanzania, Uganda, Zambia Namibia and Ghana. Cape Town: HSRC Press.

Kenya Power, \& REA. (2017). SFG3187 V1 Kenya off-grid solar access project (k-osap) environmental \& social management framework (March).

Khandker, S. R., Samad, H. A., Ali, R., \& Barnes, D. F. (2012). Who benefits most from rural electrification? Evidence in India [Internet]. World Bank policy research working paper. Washington, DC: World Bank. Retrieved from https://openknowledge.worldbank.org/handle/10986/9328

Kirubi, C., Jacobson, A., Kammen, D. M., \& Mills, A. (2009). Community-based electric micro-grids can contribute to rural development: Evidence from Kenya. World Development, 37(7), 1208-1221. doi:10.1016/J.WORLDDEV.2008.11.005

Lenz, L., Munyehirwe, A., Peters, J., \& Sievert, M. (2017). Does large-scale infrastructure investment alleviate poverty? Impacts of Rwanda's electricity access roll-out program. World Development, 89, 88-110. doi:10.1016/j.worlddev.2016.08.003

Lipscomb, M., Mobarak, A. M., \& Barham, T. (2013). Development effects of electrification: Evidence from the topographic placement of hydropower plants in Brazil. American Economic Journal: Applied Economics, 5, 200-231.

Magalini, F., Sinha-Khetriwal, D., Rochat, D., Huismann, J., Munyambu, S., Oliech, J., ... Mbera, O. (2016). Electronic waste (e-waste) impacts and mitigation options in the off-grid renewable energy sector. Retrieved from https://doi.org/10.12774/eod_cr.august2016.Magalinifetal

McCollum, D. L., Zhou, W., Bertram, C., de Boer, H.-S., Bosetti, V., Busch, S., ... Riahi, K. (2018). Energy investment needs for fulfilling the Paris Agreement and achieving the sustainable development goals. Nature Energy. doi:10.1038/s41560-018-0179-z

Ministry of Devolution and Planning of Kenya. (2017). Implementation of the agenda 2030 for sustainable development in Kenya. Retrieved from https://sustainabledevelopment.un.org/content/documents/15689Kenya.pdf

M-KOPA Solar. (2018). M-KOPA 4 technical sheet. Retrieved from www.lightingglobal.org/products/mk-mk4

Moksnes, N., Korkovelos, A., Mentis, D., \& Howells, M. (2017). Electrification pathways for Kenya-linking spatial electrification analysis and medium to long term energy planning. Environmental Research Letters, 12(9), 095008. doi:10.1088/1748-9326/aa7e18

Moner-Girona, M., Solano-Peralta, M., Lazopoulou, M., Ackom, E. K., Vallve, X., \& Szabó, S. (2018). Electrification of sub-Saharan Africa through PV/hybrid mini-grids: Reducing the gap between current business models and on-site experience. Renewable and Sustainable Energy Reviews, 91, 1148-1161. doi:10.1016/j.rser.2018.04.018

Nygaard, I., Cichungi, H., Larsen, T. H., Cronin, T., Davis, N., Chitechi, E., ... Højgaard, J. W. (2018). Market for integration of smaller wind turbines in mini-grids in Kenya draft, (May).

Olsen, K. H., Verles, M., \&Braden, S. (2018). Aligning the agendas. A party-driven dialogue on sustainable development in context of Article 6 PA. Carbon mechanisms review. Berlin: Wuppertal Institute.

Pedersen, M. B., \& Nygaard, I. (2018). System building in the Kenyan electrification regime: The case of private solar mini-grid devel- opment. Energy Research and Social Science, 42(March), 211-223.

Ponsioen, T. (2013). The surplus cost method |PRé Sustainability. Retrieved from https://www.pre-sustainability.com/news/the- surpluscost-method-introduction

Prasad, G. (2008). Energy sector reform, energy transitions and the poor in Africa. Energy Policy, 36(8), 2806-2811.

doi:10.1016/j.enpol.2008.05.018

Pueyo, A., \& DeMartino, S. (2018). The impact of solar mini-grids on Kenya's rural enterprises. Energy for Sustainable Development, 45, 2837. doi:10.1016/j.esd.2018.04.002

REA. (2016). Tender no. REA/2016-2017/NT/027 for design, supply, implementation, testing and commissioning of $25 \mathrm{no}$. $60 \mathrm{~kW}$ solar pv- diesel hybrid plants in 25no. Trading centres in off-grid areas.

Riva, F., Ahlborg, H., Hartvigsson, E., Pachauri, S., \& Colombo, E. (2018). Electricity access and rural development: Review of complex socioeconomic dynamics and causal diagrams for more appropriate energy modelling. Energy for Sustainable Development, 43, 203-223. doi:10.1016/j.esd.2018.02.003

Rom, A., Günther, I., \& Harrison, K. (2017). The economic impact of solar lighting: Results from a randomised field experiment in rural Kenya. Retrieved from https://www.ethz.ch/content/dam/ethz/special-interest/gess/nadel-dam/documents/research/ SolarLighting/17.02.24_ETHreportoneconomicimpactofsolar_summary_FINAL.pdf

Schmidt, M. (2019). Scarcity and environmental impact of mineral resources-An old and never-ending discussion. Resources, 8(1), 2. 
doi:10.3390/resources8010002

Schmidt, T. S., Blum, N. U., \& Sryantoro Wakeling, R. (2013). Attracting private investments into rural electrification - A case study on renewable energy based village grids in Indonesia. Energy for Sustainable Development, 17(6), 581-595. doi:10.1016/j.esd.2013.10. 001

Schwerhoff, G., \& Sy, M. (2017). Financing renewable energy in Africa-Key challenge of the sustainable development goals. Renewable and Sustainable Energy Reviews, 75, 393-401. doi:10.1016/J.RSER.2016.11.004

Schwerhoff, G., \& Sy, M. (2019). Developing Africa's energy mix. Climate Policy, 19(1), 108-124. doi:10.1080/14693062.2018.1459293 SE4All.

(2013). Global tracking framework. Retrieved from https://www.iea.org/publications/freepublications/publication/Global_ Tracking_Framework.pdf

Shiu, A., \& Lam, P.-L. (2004). Electricity consumption and economic growth in China. Energy Policy, 32(1), 47-54. doi:10.1016/S03014215(02)00250-1

Stern, D. I., Burke, P. J., \& Bruns, S. B. (2017). The impact of electricity on economic development: A macroeconomic perspective. Retrieved from https://escholarship.org/uc/item/7jb0015q

Szabó, S., Bódis, K., Huld, T., \& Moner-Girona, M. (2011). Energy solutions in rural Africa: Mapping electrification costs of distributed solar and diesel generation versus grid extension. Environmental Research Letters, 6(3), 034002. doi:10.1088/1748-9326/6/3/034002

UNDESA. (2014). Electricity and education: The benefits, barriers, and recommendations for achieving the electrification of primary and

secondary schools. Retrieved from https://sustainabledevelopment.un.org/content/documents/1608ElectricityandEducation.pdf

UNDP. (2012). Gender and energy. Retrieved from http://www.undp.org/content/dam/undp/library/gender/GenderandEnvironment/ PB3_Africa_Gender-and-Energy.pdf

UNFCCC. (2019). Decision 18/CMA.1. Modalities, procedures and guidelines for the transparency framework for action and support referred to in Article 13 of the Paris Agreement. Retrieved from https://unfccc.int/sites/default/files/resource/cma2018_3_add2_ new advance.pdf\#page $=18$

Unruh, G. C. (2002). Escaping carbon lock-in. Energy Policy, 30(4), 317-325. doi:10.1016/S0301-4215(01)00098-2

Van Acker, V., Szablya, S. J., Louie, H., McLean Sloughter, J., \& Pirbhai, A. S. (2014). Survey of energy use and costs in rural Kenya for community microgrid business model development. IEEE Global Humanitarian Technology Conference (GHTC 2014), 166-173. doi:10.1109/GHTC.2014.6970277

Van de Walle, D., Ravallion, M., Mendiratta, V., \& Koolwal, G. (2013). Long-term impacts of household electrification in rural India. Washington, DC: The World Bank.

WHO. (2018a). Household air pollution and health. Retrieved from http://www.who.int/news-room/fact-sheets/detail/household-air- pollutionand-health

WHO | Metrics: Disability-Adjusted Life Year (DALY). (2018b). Retrieved from https://www.who.int/healthinfo/global_burden_disease/ metrics daly/en/

Willcox, M., Pueyo, A., Waters, L., Hanna, R., Wanjiru, H., Palit, D., \& Sharma, K. R. (2015). Utilising energy access for poverty reduction, 2016(10/20). Retrieved from http://cdn1.practicalaction.org/e///54c7a51f-312c-4f20-a8e7-177c0a0000be.pdf Williams, N. J.,

Jaramillo, P., Taneja, J., \&Ustun, T.S. (2015). Enabling private sector investment in microgrid-based rural electrification in developing countries: A review. Renewable and Sustainable Energy Reviews, 52, 1268-1281. doi:10.1016/j.rser.2015.07.153

Winther, T., Ulsrud, K., \& Saini, A. (2018). Solar powered electricity access: Implications for women's empowerment in rural Kenya. Energy Research and Social Science, 44, 61-74. doi:10.1016/j.erss.2018.04.017

Wolde-Rufael, Y. (2006). Electricity consumption and economic growth: A time series experience for 17 African countries. Energy Policy, 34(10), 1106-1114. doi:10.1016/J.ENPOL.2004.10.008

World Bank. (2008). The welfare impact of rural electrification: A reassessment of the costs and benefits. Retrieved from https:/l siteresources.worldbank.org/EXTRURELECT/Resources/full_doc.pdf

World Bank. (2017). Kenya: Off-grid solar access project for underserved counties - Procurement plan. Retrieved from http:// documents.worldbank.org/curated/en/123751529386307644/Kenya-AFRICA-P160009-Kenya-Off-grid-Solar-Access-Project-for- UnderservedCounties-Procurement-Plan

World Bank. (2018a). Kenya: Off-grid solar access project for underserved counties - Implementation status \& results report, 1-8. World Bank. (2018b). Population, total | Data. Retrieved from https://data.worldbank.org/indicator/SP.POP.TOTL?locations=KE World Bank. (n.d.)

Gender equality and energy M02: Gender and energy access: Household energy and rural electrification. Retrieved from https://www.esmap.org/sites/esmap.org/files/DocumentLibrary/Gender_Energy M02.pdf

World Bank, ESMAP, \& Climate InvestmentFunds. (2017). Minigrids in Kenya. Acasestudy of amarketataturning point. Retrieved from http://documents.worldbank.org/curated/en/792001512392701402/pdf/ESM-cKenyaMiniGridsCaseStudyConfEd-PUBLIC.pdf 